\title{
Article \\ The Impact of the COVID-19 Outbreak on Patients' Adherence to PCSK9 Inhibitors Therapy
}

\author{
Valentina Maria Caso ${ }^{1}$, Simona Sperlongano ${ }^{1} \mathbb{1}$, Biagio Liccardo ${ }^{1}$, Emanuele Romeo ${ }^{1}$, Sergio Padula ${ }^{2}$, \\ Fortunato Arenga ${ }^{2}$, Antonello D'Andrea ${ }^{3}\left(\mathbb{1}\right.$, Pio Caso ${ }^{2}$, Paolo Golino ${ }^{1}$, Gerardo Nigro ${ }^{1}$ (i) \\ and Vincenzo Russo ${ }^{1, *(1)}$
}

check for

updates

Citation: Caso, V.M.; Sperlongano, S.;

Liccardo, B.; Romeo, E.; Padula, S.; Arenga, F.; D'Andrea, A.; Caso, P.; Golino, P.; Nigro, G.; et al. The Impact of the COVID-19 Outbreak on Patients' Adherence to PCSK9 Inhibitors Therapy. J. Clin. Med. 2022, 11,475. https://doi.org/10.3390/ jcm11030475

Academic Editor: Robert Flisiak

Received: 18 November 2021

Accepted: 9 January 2022

Published: 18 January 2022

Publisher's Note: MDPI stays neutral with regard to jurisdictional claims in published maps and institutional affiliations.

Copyright: (c) 2022 by the authors. Licensee MDPI, Basel, Switzerland. This article is an open access article distributed under the terms and conditions of the Creative Commons Attribution (CC BY) license (https:/ / creativecommons.org/licenses/by/ $4.0 /)$.
1 Cardiology Unit, Department of Traslational Medical Sciences, University of Campania Luigi Vanvitelli, 80131 Naples, Italy; valepica8@yahoo.it (V.M.C.); sperlongano.simona@gmail.com (S.S.); liccardob@gmail.com (B.L.); ema.romeo@virgilio.it (E.R.); paolo.golino@unicampania.it (P.G.); gerardo.nigro@unicampania.it (G.N.)

2 Division of Cardiology, Monaldi Hospital, 80131 Naples, Italy; padulas@libero.it (S.P.); fortunatoarenga@libero.it (F.A.); pio.caso@ospedalideicolli.it (P.C.)

3 Department of Cardiology and Intensive Coronary Care, Umberto I Hospital, 84014 Nocera Inferiore, Italy; antonellodandrea@libero.it

* Correspondence: vincenzo.russo@unicampania.it

\begin{abstract}
PCSK9 inhibitors (PCSK9i) are monoclonal antibodies that have been shown to be effective in reducing both LDL cholesterol (LDL-C) values and major cardiovascular events in patients at high cardiovascular risk. Adherence to PCSK9i is critical for the success of the treatment. The aim of the present study is to evaluate patients' adherence to PCSK9i during the COVID-19 pandemic. Patients referred to the Cardiac Diagnostic Unit of the University of Campania "Luigi Vanvitelli" Naples, taking PCSK9i, and who missed the cardiological follow-up visit during the first national COVID-19 lockdown (9 March-17 May 2020), were included. Each patient underwent medical teleconsultation to collect current clinical conditions, adherence to drug treatments, and lipid profile laboratory tests. Among 151 eligible patients, 20 were excluded for missing or untraceable telephone numbers and one for refusing to join the interview. The selected study population consisted of 130 patients (64 \pm 9 years, $68 \%$ males), of whom 11 (8.5\%) reported a temporary interruption of the PCSK-9 therapy for a mean period of $65 \pm 1.5$ days. The non-adherent patients showed a marked increase in LDL-C than in the pre-pandemic period (90.8 \pm 6.0 vs. $54.4 \pm 7.7 \mathrm{mg} / \mathrm{dL}, p<0.0001$ ), and $82 \%$ of patients moved out of the LDL-C therapeutic range. The non-adherent group was more likely to have a very high cardiovascular risk compared to the adherent group ( $81.8 \mathrm{vs} .33 .6 \%, p<0.001)$. Causes of interruption included drug prescription failure $(63.6 \%)$ due to temporary interruption of the non-urgent outpatient visits and failure in drug withdrawal $(36.4 \%)$ due to patients' fear of becoming infected during the pandemic. The COVID-19 lockdown caused a remarkable lack of adherence to PCSK9i therapy, risking negative implications for the health status of patients at high cardiovascular risk. Facilitating patients' access to PCSK9i and enhancing telemedicine seem to be effective strategies to ensure the continuity of care and appropriate management of these patients.
\end{abstract}

Keywords: COVID-19; PCSK9 inhibitors; adherence; lockdown

\section{Introduction}

The coronavirus disease 2019 (COVID-19) pandemic is a global health emergency caused by the severe acute respiratory syndrome coronavirus 2 (SARS-CoV-2) [1]. The clinical course of the disease can be asymptomatic or complicated by the onset of severe respiratory distress syndrome and/or multi-organ failure that may require hospitalization [2,3]. In attempting to contain the virus spread, the Italian Government adopted strict rules, including the national lockdown from 9 March 2020 to 17 May 2020 [4]. During this period, non-urgent clinic visits or cardiac interventional procedures were postponed to a later date 
and changes in the patterns of hospital admissions in Italy were observed [5-8]. To date, no data have been provided on the adherence to cardiovascular $(\mathrm{CV})$ pharmacotherapy during the COVID-19 outbreak.

Among the CV therapies, proprotein convertase subtilisin/kexin 9 inhibitors (PCSK9i) are a new class of lipid-lowering drugs, which proved to be effective in reducing low-density lipoprotein cholesterol (LDL-C) and CV events in high-risk patients [9,10]. PCSK9i have a convenient administration regimen (subcutaneously, bi-weekly, or monthly) and a favorable adverse effects profile, with no risk of new-onset diabetes or cognitive deficits [9-12]. For these reasons, they are currently recommended, alone or in combination therapy with high-intensity statin and/or ezetimibe, for patients at high and very high CV risk [13]. These patients require close medical follow-up and strict treatment adherence, aiming to lower LDL-C as much as possible and reduce the residual atherothrombotic risk [14-16]. The aim of the present study is to describe patients' adherence to PCSK9i during the COVID-19 pandemic.

\section{Materials and Methods}

\subsection{Study Design and Study Population}

Patients frequently undertaking PCSK9i therapy at the Cardiac Diagnostic Unit of the University of Campania "Luigi Vanvitelli", and who missed the follow-up visit from 9 March 2020 and 17 May 2020, due to the COVID-19 pandemic lockdown restrictions, were retrospectively selected from the hospital healthcare database. Patients with missing telephone numbers, untraceable patients, and patients who did not give their informed consent were excluded.

\subsection{Teleconsultation and Data Collection}

Each patient underwent a semi-structured telephonic interview. The following clinical data were collected: comorbidities, recent medical history, pharmacological treatments, drugs adherence, and reasons for therapy discontinuation. All patients were also asked to send by dedicated email address or mobile number the blood laboratory tests they should have exhibited during the missed follow-up visit including total cholesterol, LDL-C, highdensity lipoprotein cholesterol (HDL-C), and triglycerides. A CV risk profile was assigned to each patient, according to the most recent European guidelines on the management of dyslipidemias [13].

PCSK9i dispensation to patients before and during lockdown was checked on a dedicated digital platform made available by the Italian Medicines Agency (AIFA).

\subsection{Primary and Secondary Outcomes}

The primary outcome of the study was to evaluate the patients' adherence to PCSK9i during the COVID-19 outbreak. The changes in lipid profile on treatment or after PCSK9i discontinuation were assessed as a secondary outcome.

\subsection{Satistical Analysis}

Kolmogorov-Smirnov and Shapiro-Wilk tests were used to evaluate the distribution of continuous data. Normally distributed variables were expressed as the mean \pm standard deviation (SD), whereas non-normal distributed ones as the median and interquartile range (IQR). Categorical variables were reported as numbers and percentages. Continuous normally distributed variables were compared using the Student $t$-test; differences between non-normally distributed variables were tested with the Mann-Whitney U test. Categorical variables were compared with the chi-squared test, or Fisher exact test, when appropriate. For all tests, a $p$-value $<0.05$ was considered statistically significant. Analyses were performed using R version 3.5.1 (R Foundation for Statistical Computing, Vienna, Austria). Patients' adherence to treatment was measured through the medication possession ratio (MPR), dividing the total number of treatment days by the specific time of monitoring [17]. 


\subsection{Ethics Approval}

The study was conducted in accordance with the declaration of Helsinki and was approved by the local ethical committee (AOC-0035368-2020). Written informed consent was obtained from all study participants before data collection.

\section{Results}

There were 151 patients on PCSK9i therapy selected for inclusion from the hospital healthcare database, with 12 patients $(7.9 \%)$ excluded for missing, 8 (5.3\%) for untraceable telephone numbers, and 1 patient $(0.7 \%)$ for refusing to join the interview. Finally, a total of 130 patients $(63.5 \pm 9.3$ years, $68.5 \%$ males $)$ who completed the phone interview and sent their blood exams by email or message were included in the study (Figure 1).

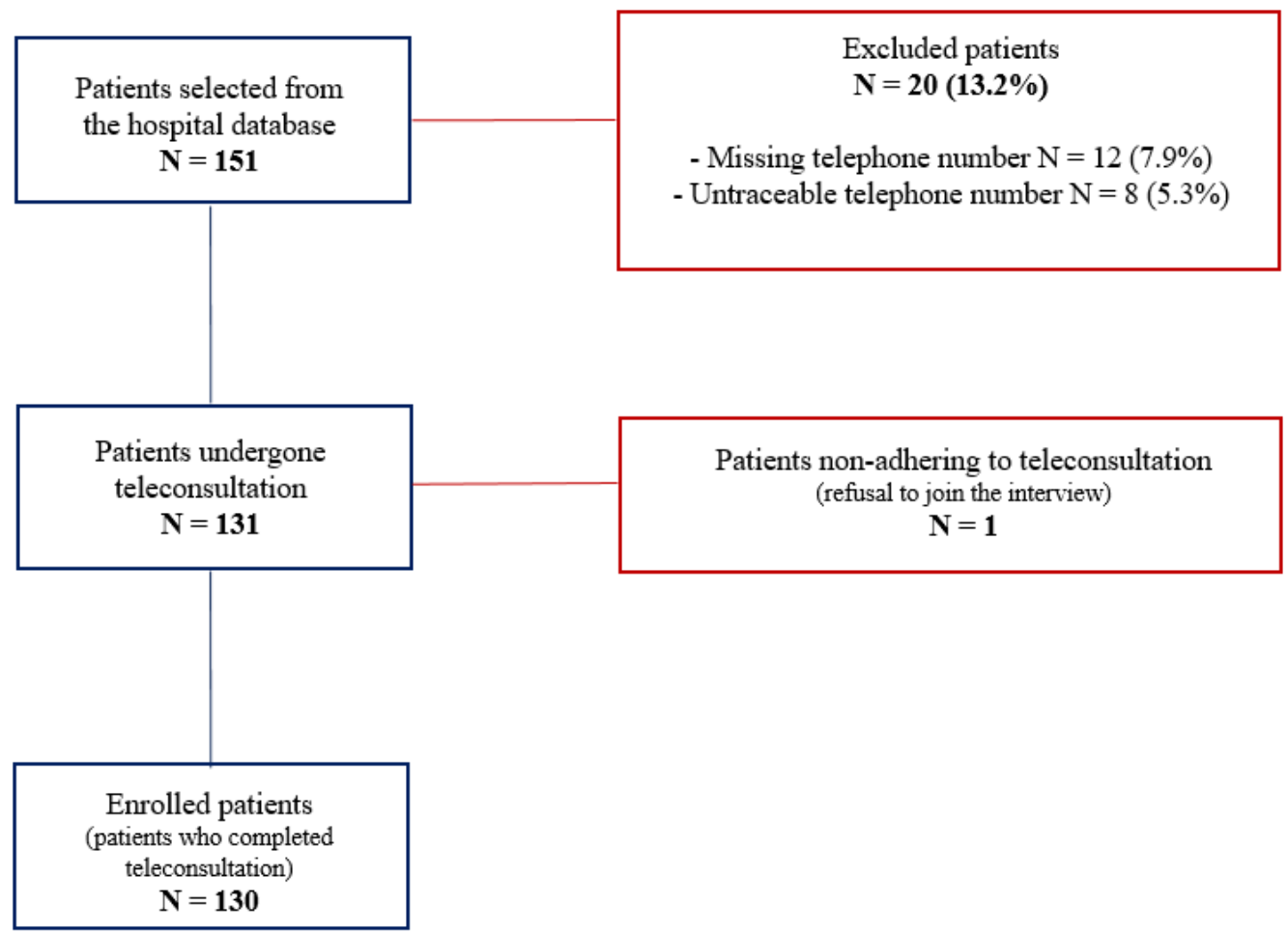

Figure 1. Inclusion graph of the study population.

All patients were taking Evolocumab 140 mg every 15 days; 15 patients $(11.5 \%)$ for primary prevention, and 115 (88.5\%) for secondary prevention. At the time of study entry, the mean duration of PCSK9i therapy was $11 \pm 3.4$ months. Evolocumab was taken in monotherapy by 15 (11.5\%) out of 130 patients due to statin intolerance. In the other cases, it was taken in combination with statins and/or other lipid-lowering therapies. Concomitant drugs of the study population are shown in Appendix A, Tables A1 and A2.

There were 11 out of 130 patients $(8.5 \%)$ who temporarily interrupted the Evolocumab therapy for a mean time of $65 \pm 1.5$ days and were considered the non-adherent group. No other drugs were discontinued, including the non-vitamin $\mathrm{K}$ antagonist oral anticoagulants (NOACs).

The causes of PCSK9i discontinuation were a failure in drug's prescription due to temporary interruption of the non-urgent outpatient visits $(n: 7 ; 63.6 \%)$ and a failure in the drug's withdrawal due to patients' fear of becoming infected by leaving the house or taking public transport during COVID-19 ( $n$ : 4; 36.4\%).

The pre-pandemic clinical characteristics of the overall population and the comparison between the adherent and non-adherent groups are reported in Table 1. 
Table 1. Pre-lockdown, clinical characteristics of the overall study population, and comparison between adherent and non-adherent groups.

\begin{tabular}{|c|c|c|c|c|}
\hline Variables & $\begin{array}{l}\text { Overall Population } \\
\quad(n=130)\end{array}$ & $\begin{array}{l}\text { Adherent Group } \\
\qquad(n=119)\end{array}$ & $\begin{array}{l}\text { Non-Adherent Group } \\
\qquad(n=11)\end{array}$ & $p$-Value \\
\hline Age (years), mean \pm SD & $63.5 \pm 9.3$ & $68 \pm 4.5$ & $61.3 \pm 5.9$ & $<0.001$ \\
\hline Male, $n(\%)$ & $89(68.5)$ & $84(70.6)$ & $6(54.5)$ & 0.3 \\
\hline Smokers, $n(\%)$ & $24(18.5)$ & $77(64.7)$ & $11(100)$ & 0.01 \\
\hline Hypertension, $n(\%)$ & $88(67.7)$ & $18(15.1)$ & $6(54.5)$ & $<0.001$ \\
\hline Obesity, $n(\%)$ & $4(3.1)$ & $3(2.5)$ & $1(9.1)$ & 0.2 \\
\hline Familial hypercholesterolemia, $n(\%)$ & $15(11.5)$ & $14(11.8)$ & $1(9.1)$ & 0.8 \\
\hline Diabetes mellitus type $2, n(\%)$ & $21(16.1)$ & $1(0.8)$ & $0(0)$ & 0.8 \\
\hline Coronary artery disease, $n(\%)$ & $102(78.5)$ & $93(78.1)$ & $9(81.8)$ & 0.8 \\
\hline Stroke, $n(\%)$ & $1(0.8)$ & $20(16.8)$ & $1(9.1)$ & 0.5 \\
\hline Peripheral arterial disease, $n(\%)$ & $35(26.9)$ & $34(28.6)$ & $1(9.1)$ & 0.2 \\
\hline Atrial fibrillation, $n(\%)$ & $2(1.5)$ & $2(1.7)$ & $0(0)$ & 0.7 \\
\hline Carotid atherosclerosis, $n(\%)$ & $10(7.7)$ & $9(7.6)$ & $1(9.1)$ & 0.8 \\
\hline $\begin{array}{l}\text { Chronic obstructive pulmonary } \\
\text { disease, } n(\%)\end{array}$ & $4(3.1)$ & $3(2.5)$ & $1(9.1)$ & 0.2 \\
\hline High risk, $n(\%)$ & $53(40.8)$ & $51(42.8)$ & $2(18.1)$ & 0.11 \\
\hline Very high risk, $n(\%)$ & $49(37.7)$ & $40(33.6)$ & $9(81.8)$ & $<0.001$ \\
\hline Moderate risk, $n(\%)$ & $28(21.5)$ & $28(23.5)$ & 0 & 0.07 \\
\hline Patients on LDL-C target, $n(\%)$ & $123(94.6)$ & $112(94.1)$ & $11(100)$ & 0.4 \\
\hline Beta blockers, $n(\%)$ & $74(56.9)$ & $63(52.9)$ & $11(100)$ & 0.003 \\
\hline Antiplatelet drugs, $n(\%)$ & $90(69.2)$ & $80(67.2)$ & $10(90.9)$ & 0.1 \\
\hline ACE inhibitors, $n(\%)$ & $41(31.5)$ & $38(31.9)$ & $3(27.3)$ & 0.7 \\
\hline Angiotensin II receptor blockers, $n(\%)$ & $33(25.4)$ & $32(26.9)$ & $1(9.1)$ & 0.2 \\
\hline Calcium channel blockers, $n(\%)$ & $15(11.5)$ & $14(11.8)$ & $1(9.1)$ & 0.8 \\
\hline Diuretics, $n(\%)$ & $43(33.1)$ & $37(31.1)$ & $6(54.5)$ & 0.1 \\
\hline $\begin{array}{c}\text { Non-vitamin K antagonist oral } \\
\text { anticoagulants } n(\%)\end{array}$ & $6(4.6)$ & $5(4.2)$ & $1(9.1)$ & 0.5 \\
\hline Class III antiarrhythmics, $n(\%)$ & $6(4.6)$ & $6(5.04)$ & $0(0)$ & 0.4 \\
\hline Insulin, $n(\%)$ & $6(4.6)$ & $6(5.04)$ & $0(0)$ & 0.4 \\
\hline Alpha blockers, $n(\%)$ & $5(3.8)$ & $5(4.2)$ & $0(0)$ & 0.9 \\
\hline Antianginal drugs, $n(\%)$ & $7(5.4)$ & $6(5.04)$ & $1(9.1)$ & 0.6 \\
\hline Antigout drugs, $n(\%)$ & $5(3.8)$ & $5(4.2)$ & $0(0)$ & 0.5 \\
\hline Glucocorticoids, $n(\%)$ & $1(0.8)$ & $1(0.8)$ & $0(0)$ & 0.8 \\
\hline Levothyroxine, $n(\%)$ & $6(4.6)$ & $6(5.04)$ & $0(0)$ & 0.4 \\
\hline Heparin, $n(\%)$ & $1(0.8)$ & $1(0.8)$ & $0(0)$ & 0.8 \\
\hline Antiepileptic drugs, $n(\%)$ & $1(0.8)$ & $1(0.8)$ & $0(0)$ & 0.8 \\
\hline Proton pump inhibitors, $n(\%)$ & $64(49.2)$ & $54(45.4)$ & $10(91)$ & 0.004 \\
\hline Statins, $n(\%)$ & $100(76.9)$ & $90(75.6)$ & $10(91)$ & $<0.001$ \\
\hline Ezetimibe, $n(\%)$ & $78(60)$ & $67(56.3)$ & $11(100)$ & 0.005 \\
\hline
\end{tabular}

Non-adherent patients were younger than adherents (61.3 vs. 68 years, $p<0.01)$ and showed higher prevalence of smokers (100 vs. $64.7 \%, p=0.01)$, systemic arterial hypertension ( 54.5 vs. $15.1 \%, p<0.01)$, use of beta-blockers (100 vs. $52.9 \%, p=0.003)$, proton pump inhibitors ( 91 vs. $45.4 \%, p=0.004$ ), statins (91 vs. $75.6 \%, p<0.001$ ), and ezetimibe (100 vs. $56.3 \%, p=0.005)$, and patients at very high risk ( $81.8 \%$ vs. $33.6 \%, p<0.01)$ At follow-up, the non-adherent group showed a significant increase in total cholesterol (158.2 vs. $129 \mathrm{mg} / \mathrm{dL}, p<0.001)$, LDL-C (90.8 vs. $54.4 \mathrm{mg} / \mathrm{dL}, p<0.001)$ and triglycerides (162.8 vs. $134 \mathrm{mg} / \mathrm{dL}, p<0.001$ ) plasma levels, and a marked decrease in HDL-C plasma levels (39.8 vs. $52.8 \mathrm{mg} / \mathrm{dL}, p<0.001$ ), compared to pre-pandemic values (Figures 2 and 3). 

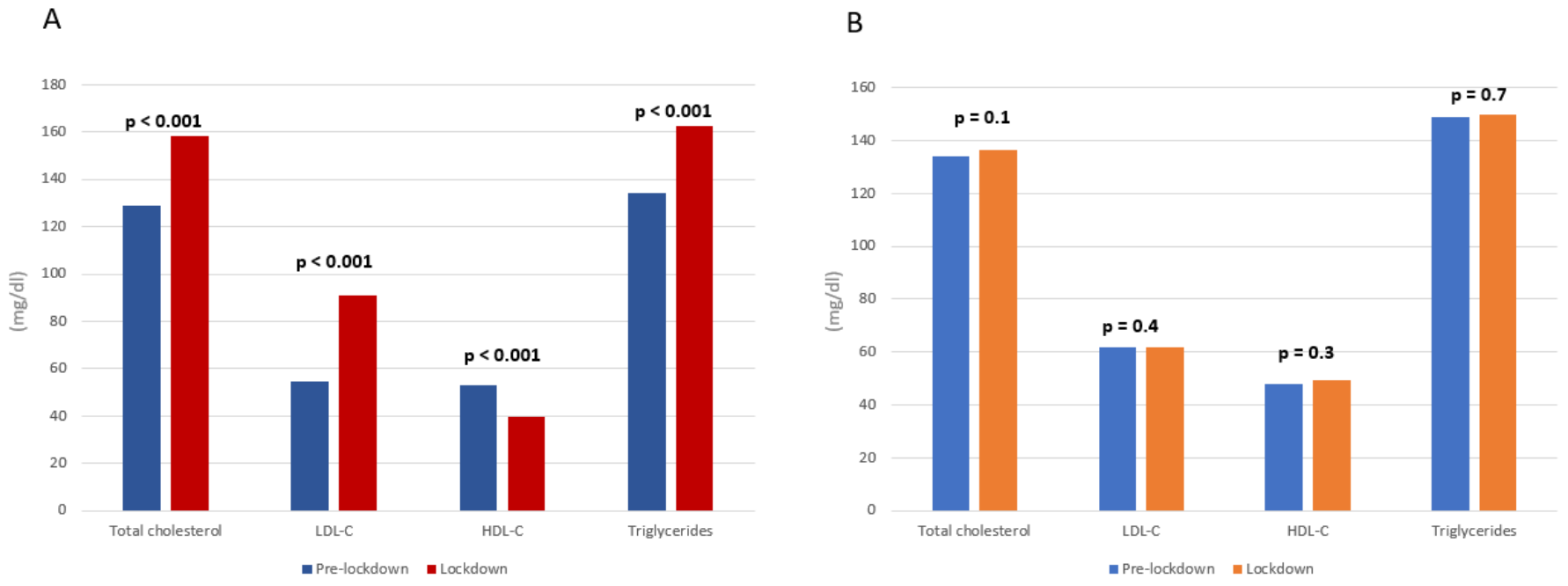

Figure 2. Lipid values changes between pre- and lockdown period in PCSK9i non-adherent (panel (A)) and adherent (panel (B)) group.

A

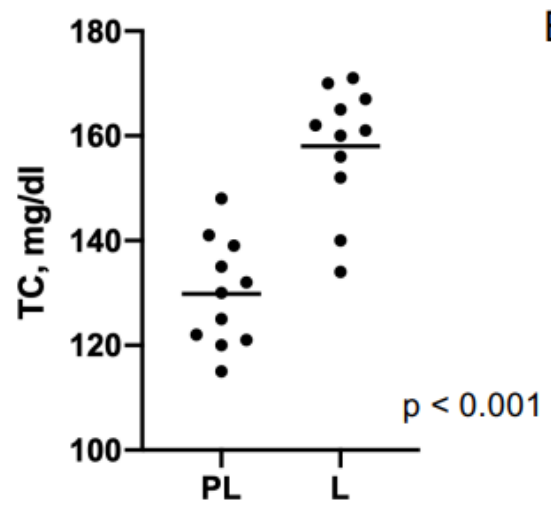

C

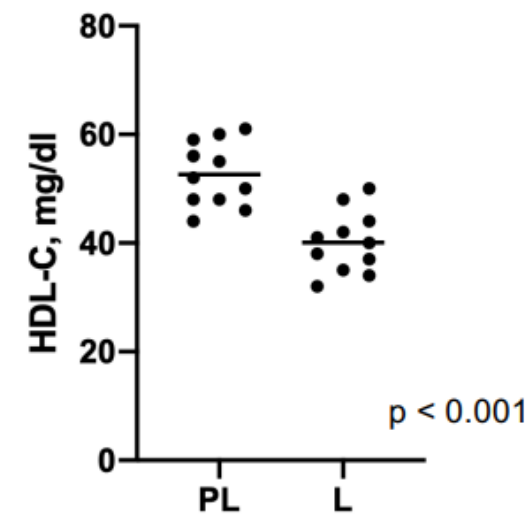

B

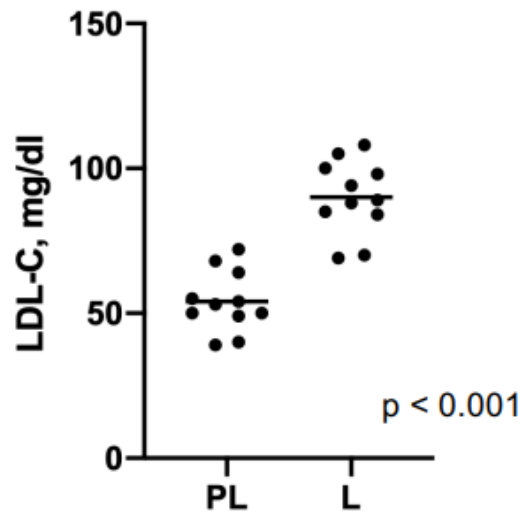

D

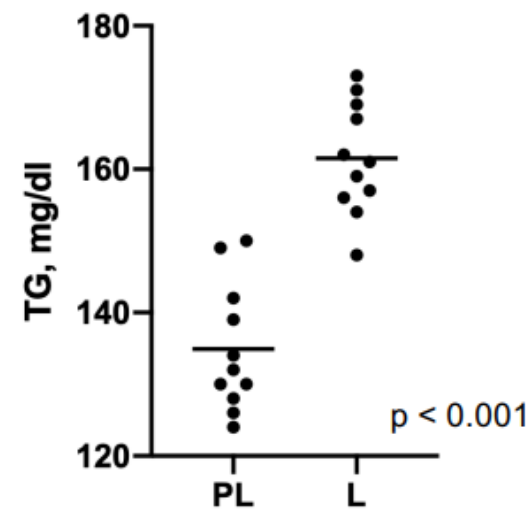

Figure 3. Scatter plots of pre-lockdown (PL) and lockdown (L) lipid values of non-adherent patients. TC: total cholesterol (panel (A)); LDL-C: LDL cholesterol (panel (B)); HDL-C: HDL cholesterol (panel (C)); TG: triglycerides (panel (D)).

No changes in lipid profile were observed in the adherent group. The lipid blood values of both groups before the pandemic and during the lockdown are shown in Table 2. 
Table 2. Changes in blood lipid values in PCSK9i adherent and non-adherent patients.

\begin{tabular}{|c|c|c|c|c|}
\hline & Lipid, mg/dL & Pre-Lockdown & Lockdown & $p$-Value \\
\hline \multirow{4}{*}{$\begin{array}{l}\text { Adherent group } \\
\qquad(n=119)\end{array}$} & Total cholesterol & $134 \pm 12$ & $136.5 \pm 14$ & 0.1 \\
\hline & LDL-cholesterol & 61.6. \pm 3.2 & $62 \pm 3.6$ & 0.4 \\
\hline & HDL-cholesterol & $47.8 \pm 12.1$ & $49.3 \pm 12.4$ & 0.3 \\
\hline & Triglycerides & $149 \pm 21.9$ & $150 \pm 22$ & 0.7 \\
\hline \multirow{4}{*}{$\begin{array}{l}\text { Non-adherent group } \\
\qquad(n=11)\end{array}$} & Total cholesterol & $129 \pm 9.8$ & $158.2 \pm 11.4$ & $<0.0001$ \\
\hline & LDL-cholesterol & $54.4 \pm 7.7$ & $90.8 \pm 6.02$ & $<0.0001$ \\
\hline & HDL-cholesterol & $52.8 \pm 5$ & $39.8 \pm 4.7$ & $<0.0001$ \\
\hline & Triglycerides & $134 \pm 8.8$ & $162.3 \pm 7$ & $<0.0001$ \\
\hline
\end{tabular}

At baseline, all of the 11 patients of the non-adherent group were in LDL-C therapeutic range, according to their $\mathrm{CV}$ risk. During follow-up, 9 patients (82\%) did not reach the target anymore $(p=0.0002)$. Regarding the adherent group, no significant difference in LDL-C target loss was found during follow-up (7 vs. 9 patients, $p=0.797$ ).

\section{Discussion}

The main findings emerging from this study include that $8.5 \%$ of patients on PCSK9i were non-adherent to therapy during COVID-19 lockdown. The leading causes of nonadherence to PCSK9i were failure in drug's prescription due to temporary interruption of the non-urgent outpatient visits and failure in drug's withdrawal due to patients' fear of becoming infected during the pandemic. The non-adherent population showed an increase in LDL-C of about $67 \% ; 82 \%$ of non-adherent patients moved out of the LDL-C therapeutic range during the lockdown.

It is well known that LDL-C is a causal factor for atherosclerosis; in particular, the effect of LDL-C on the risk of atherosclerotic CV disease (ASCVD) is determined by both the absolute magnitude and the total duration of exposure to LDL-C [18]. Lowering LDL-C blood values reduces the risk of ASCVD proportionally to the absolute achieved reduction in LDL-C $[18,19]$. The current European Guidelines for the management of dyslipidemias [13] recommend $>50 \%$ reduction in LDL-C from the baseline in patients at high and very high CV risk, with strict treatment goals for LDL-C absolute values ( $<70 \mathrm{mg} / \mathrm{dL}$ and $<55 \mathrm{mg} / \mathrm{dL}$, respectively).

PCSK9i are effective and safe lipid-lowering drugs, recommended for secondary or primary prevention in patients at high CV risk not achieving their LDL-C goal on a maximum tolerated dose of statin and ezetimibe [13]. The commercially available PCSK9i, Alirocumab and Evolocumab, have been shown to significantly reduce LDL-C levels on average by $60 \%$ if administered alone and by $85 \%$ if administered with high-intensity statin and ezetimibe. More importantly, both proved to reduce the risk of CV events $[9,10]$. Moreover, PCSK9i demonstrated a higher level of adherence than statins, likely due to their favorable administration regimen, low rates of adverse effects, the opportunity to use a lower (more tolerable) statin dosage, and the patient's perception that injecting therapy is more effective than oral [20]. Despite this evidence and the European guidelines recommendations, the rate of prescription of PCSK9 inhibitors appears below expectations, mainly due to national rules governing their reimbursement.

Moreover, during the COVID-19 outbreak, reduced adherence to PCSK9i therapy was observed, with a subsequent increase in LDL-C blood values of high CV risk patients. This phenomenon may be due to the strict limitations by the AIFA for national pharmacovigilance purposes concerning PCSK9i use [21]. Currently, only a few physicians are authorized to prescribe these drugs in Italy. 
Moreover, the PCSK9i's distribution occurs exclusively through the hospital pharmacies of the Local Health Authorities. Finally, the hospital pharmacist has to promptly communicate the occurred PCSK9i's dispensation to AIFA in order to allow the following drug prescriptions.

This complex mechanism creates a PCSK9i access barrier, especially during a national health emergency, such as the COVID-19 pandemic.

Simplifying patients' access to PCSK9i can be a strategy to reduce the risk of treatment discontinuation and ensure continuity of care. This goal could be achieved by increasing the number of physicians authorized for PCSK9i prescription and by involving several private territorial pharmacies in the drug's distribution system.

Telemedicine proved to be a simple and well-tolerated tool for ensuring continuity of care and the outpatient management of patients with CV diseases during the COVID-19 pandemic [22,23]. Many telecommunication tools (e.g., live video conferencing, phone calls, remote monitoring of implanted or wearable devices) have been used to collect diagnostic and prognostic data when an in-hospital follow-up visit was not performed [22,24]. The use of telemedicine is of pivotal importance during public health emergencies such as COVID-19, where social distancing is mandatory, permitting patients to avoid direct physical contact, diminishing exposure to respiratory secretions, and minimizing the risk of virus transmission [25]. Its role becomes crucial in the clinical management of chronic diseases, such as $\mathrm{CV}$ diseases, which require many follow-up visits, potentially increasing the risk of infection.

Based on these considerations, it would be desirable to officially recognize the telemedicine service, addressing the concerns related to reimbursement policies and licensing laws in Italy. Furthermore, specialized professionals should be trained and educated as interviewers to ensure clear and effective communication with patients and successful data collection. Moreover, the activation of a national program for the digital literacy of the elderly is needed to increase adherence to telemedicine services.

\section{Conclusions}

The COVID-19 lockdown caused a remarkable lack of adherence to PCSK9i therapy, risking negative implications for the health status of high-risk patients with chronic $\mathrm{CV}$ diseases. Some strategies may be proposed to ensure continuity of care and the appropriate management of patients with high residual atherothrombotic risk, such as removing the barriers to PCSK9i prescription and patient access and enhancing the telemedicine services.

Author Contributions: Conceptualization, V.R.; methodology, V.R.; software, B.L. and E.R.; validation, P.G., G.N. and P.C.; formal analysis, S.S.; investigation, V.M.C.; resources, F.A.; data curation, S.S.; writing - original draft preparation, V.M.C. and S.S.; writing - review and editing, V.R.; visualization, S.P.; supervision, A.D.; project administration, G.N.; funding acquisition, P.G. All authors have read and agreed to the published version of the manuscript.

Funding: This research received no external funding.

Institutional Review Board Statement: The study was conducted according to the guidelines of the Declaration of Helsinki, and approved by the Institutional Review Board of Monaldi Hospital (AOC-0035368-2020).

Informed Consent Statement: Informed consent was obtained from all subjects involved in the study.

Data Availability Statement: The data presented in this study are available on request from the corresponding author.

Conflicts of Interest: The authors declare no conflict of interest. 


\section{Appendix A}

Table A1. Concomitant lipid lowering therapies.

\begin{tabular}{cc}
\hline Concomitant Lipid Lowering Drugs & N (\%) \\
\hline Ezetimibe $10 \mathrm{mg}, n(\%)$ & $15(11.5)$ \\
\hline Atorvastatin $40 \mathrm{mg}, n(\%)$ & $14(10.8)$ \\
\hline Rosuvastatin $40 \mathrm{mg}, n(\%)$ & $15(11.5)$ \\
\hline Rosuvastatin $20 \mathrm{mg}, n(\%)$ & $2(1.5)$ \\
\hline Rosuvastatin $10 \mathrm{mg}, n(\%)$ & $10(7.7)$ \\
\hline Atorvastatin $20 \mathrm{mg}+$ Ezetimibe $10 \mathrm{mg}, n(\%)$ & $20(15.4)$ \\
\hline Atorvastatin $40 \mathrm{mg}+$ Ezetimibe $10 \mathrm{mg}, n(\%)$ & $8(6.2)$ \\
\hline Simvastatin $20 \mathrm{mg}+$ Ezetimibe $10 \mathrm{mg}, n(\%)$ & $12(9.2)$ \\
\hline Simvastatin $40 \mathrm{mg}+$ Ezetimibe $10 \mathrm{mg}, n(\%)$ & $5(3.8)$ \\
\hline Rosuvastatin $10 \mathrm{mg}+$ Ezetimibe $10 \mathrm{mg}, n(\%)$ & $8(6.2)$ \\
\hline Rosuvastatin $20 \mathrm{mg}+$ Ezetimibe $10 \mathrm{mg}, n(\%)$ & 6 \\
\hline
\end{tabular}

Table A2. Concomitant non-lipid lowering therapies.

\begin{tabular}{lc}
\hline \multicolumn{1}{c}{ Concomitant Drugs } & $\mathbf{N}(\mathbf{\%})$ \\
\hline Beta-blockers & $53(40.8)$ \\
- Bisoprolol & $7(5.4)$ \\
- Nebivolol & $6(4.6)$ \\
- Metoprolol & $5(3.8)$ \\
- Carvedilol & $3(2.3)$ \\
- Atenolol & \\
\hline Antiplatelet agents & $49(37.7)$ \\
- Acetylsalicylic acid & $9(6.9)$ \\
- Clopidogrel & $13(10)$ \\
- Ticagrerol & $19(14.6)$ \\
- Clopidogrel + acetylsalicylic acid & \\
\hline ACE- inhibitors & $30(23.1)$ \\
- Ramipril & $6(4.6)$ \\
- Lisinopril & $5(3.8)$ \\
- Enalapril & \\
\hline Angiotensin II receptor-blockers & $9(6.9)$ \\
- Losartan & $11(8.5)$ \\
- Olmesartan & $7(5.4)$ \\
- Telmisartan & $6(4.6)$ \\
- Valsartan & \\
\hline Calcium channel-blockers & $14(10.8)$ \\
- Amlodipine & $1(0.8)$ \\
- Lercandipine & \\
\hline Diuretics & $17(13)$ \\
- Thiazide diuretics & $14(10.8)$ \\
- Loop diuretics & $1(0.8)$ \\
- Potassium sparing diuretics & $9(6.9)$ \\
- Carbonic anhydrase inhibitors & \\
- Osmotic diuretics & \\
\hline
\end{tabular}


Table A2. Cont.

\begin{tabular}{lc}
\hline \multicolumn{1}{c}{ Concomitant Drugs } & $\mathbf{N}(\%)$ \\
\hline Non-vitamin K oral anticoagulants & $3(2.3)$ \\
- Apixaban & $2(1.5)$ \\
- Rivaroxaban & $1(0.8)$ \\
- Dabigatran & \\
\hline Class III antiarrhythmics & $6(4.6)$ \\
- Amiodarone & \\
\hline Oral antidiabetics & $8(6.1)$ \\
- Biguanide & $2(1.5)$ \\
- Sulfonylureas & $6(4.6)$ \\
\hline Insulin & \\
\hline Alpha-blockers & $5(3.8)$ \\
- Doxazosine & $7(5.4)$ \\
\hline Antianginal agents & \\
- Ranolazine & $5(3.8)$ \\
\hline Antigout drugs & \\
- Febuxostat & $1(0.8)$ \\
\hline Glucocorticoids & $6(4.6)$ \\
- Prednisolone & $1(0.8)$ \\
\hline Levothyroxine & $1(0.8)$ \\
\hline Heparin & $14(10.8)$ \\
\hline Antiepileptic drugs & $44(33.8)$ \\
\hline Proton pump inhibitors & \\
- Omeprazole & \\
- Pantoprazole & \\
- Esomeprazole & \\
- Lansoprazole & \\
\hline & \\
\hline & \\
\hline
\end{tabular}

\section{References}

1. Hui, D.; Azhar, E.; Madani, T.A.; Ntoumi, F.; Kock, R.; Dar, O.; Ippolito, G.; McHugh, T.D.; Memish, Z.A.; Drosten, C.; et al. The continuing 2019-nCoV epidemic threat of novel coronaviruses to global health-The latest 2019 novel coronavirus outbreak in Wuhan, China. Int. J. Infect. Dis. 2020, 91, 264-266. [CrossRef]

2. Russo, V.; Bottino, R.; Carbone, A.; Rago, A.; Papa, A.A.; Golino, P.; Nigro, G. COVID-19 and Heart: From Clinical Features to Pharmacological Implications. J. Clin. Med. 2020, 9, 1944. [CrossRef] [PubMed]

3. Russo, V.; Piccinocchi, G.; Mandaliti, V.; Annunziata, S.; Cimmino, G.; Attena, E.; Moio, N.; Di Micco, P.; Severino, S.; Trotta, R.; et al. Cardiovascular Comorbidities and Pharmacological Treatments of COVID-19 Patients Not Requiring Hospitalization. Int. J. Environ. Res. Public Health 2020, 18, 102. [CrossRef]

4. Available online: www.gazzettaufficiale.it/eli/id/2020/03/09/20A01558/sg (accessed on 15 November 2021).

5. Russo, V.; Pafundi, P.C.; Rapacciuolo, A.; D'andrea, A.; de Devitiis, M.; Volpicelli, M.; Ruocco, A.; Nigro, G.; D'onofrio, A. Arrhythmogenic syncope leading to cardiac rhythm management procedures during COVID-19 lockdown. Expert Rev. Med. Devices 2020, 17, 1207-1210. [CrossRef] [PubMed]

6. Russo, V.; Pafundi, P.C.; Rapacciuolo, A.; de Divitiis, M.; Volpicelli, M.; Ruocco, A.; Rago, A.; Uran, C.; Nappi, F.; Attena, E.; et al. Cardiac pacing procedures during coronavirus disease 2019 lockdown in Southern Italy. J. Cardiovasc. Med. 2021, 22, 857-859. [CrossRef]

7. De Rosa, S.; Spaccarotella, C.; Basso, C.; Calabrò, M.P.; Curcio, A.; Filardi, P.P.; Mancone, M.; Mercuro, G.; Muscoli, S.; Nodari, S.; et al. Reduction of hospitalizations for myocardial infarction in Italy in the COVID-19 era. Eur. Heart J. 2020, 41, 2083-2088. [CrossRef]

8. Russo, V.; Boggian, G.; Bolognesi, M.G.; Carretta, D.M.; Cencetti, S.; De Laura, D.; Hrovatin, E.; Pastori, P.; Tomaselli, C.; Parente, E.; et al. The Impact of COVID-19 Outbreak on Syncope Units Activities in Italy: A Report from the Italian Multidisciplinary Working Group on Syncope (GIMSI). Int. J. Environ. Res. Public Health 2021, 18, 9194. [CrossRef] 
9. Schwartz, G.G.; Steg, P.G.; Szarek, M.; Bhatt, D.L.; Bittner, V.A.; Diaz, R.; Edelberg, J.M.; Goodman, S.G.; Hanotin, C.; Harrington, R.A.; et al. Alirocumab and Cardiovascular Outcomes after Acute Coronary Syndrome. N. Engl. J. Med. 2018, 379, 2097-2107. [CrossRef] [PubMed]

10. Sabatine, M.S.; Giugliano, R.P.; Keech, A.C.; Honarpour, N.; Wiviott, S.D.; Murphy, S.A.; Kuder, J.F.; Wang, H.; Liu, T.; Wasserman, S.M.; et al. Evolocumab and Clinical Outcomes in Patients with Cardiovascular Disease. N. Engl. J. Med. 2017, 376, 1713-1722. [CrossRef] [PubMed]

11. Sabatine, M.S.; Leiter, L.; Wiviott, S.D.; Giugliano, R.; Deedwania, P.; De Ferrari, G.M.; Murphy, S.; Kuder, J.F.; Gouni-Berthold, I.; Lewis, B.S.; et al. Cardiovascular safety and efficacy of the PCSK9 inhibitor evolocumab in patients with and without diabetes and the effect of evolocumab on glycaemia and risk of new-onset diabetes: A prespecified analysis of the FOURIER randomised controlled trial. Lancet Diabetes Endocrinol. 2017, 5, 941-950. [CrossRef]

12. Giugliano, R.P.; Mach, F.; Zavitz, K.; Kurtz, C.; Narimon, H.; Kanevsky, E.; Schneider, J.; Wang, H.; Keech, A.; Pedersen, T.R.; et al Cognitive Function in a Randomized Trial of Evolocumab. N. Engl. J. Med. 2017, 377, 633-643. [CrossRef]

13. Mach, F.; Baigent, C.; Catapano, A.L.; Koskinas, K.C.; Casula, M.; Badimon, L.; Chapman, M.J.; De Backer, G.G.; Delgado, V.; Ference, B.A.; et al. 2019 ESC/EAS Guidelines for the management of dyslipidaemias: Lipid modification to reduce cardiovascular risk. Eur. Heart J. 2020, 41, 111-188. [CrossRef]

14. Baigent, C.; Blackwell, L.; Emberson, J.; Holland, L.E.; Reith, C.; Bhala, N.; Peto, R.; Barnes, E.H.; Keech, A.; Cholesterol Treatment Trialists' (CTT) Collaboration. Efficacy and safety of more intensive lowering of LDL cholesterol: A meta-analysis of data from 170000 participants in 26 randomised trials. Lancet 2010, 376, 1670-1681. [CrossRef]

15. Hsia, J.; MacFadyen, J.G.; Monyak, J.; Ridker, P.M. Cardiovascular event reduction and adverse events among subjects attaining low-density lipoprotein cholesterol $<50 \mathrm{mg} / \mathrm{dL}$ with rosuvastatin. The JUPITER trial (Justification for the Use of Statins in Prevention: An Intervention Trial Evaluating Rosuvastatin). J. Am. Coll. Cardiol. 2011, 57, 1666-1675. [CrossRef]

16. McCormack, T.; Dent, R.; Blagden, M. Very low LDL-C levels may safely provide additional clinical cardiovascular benefit: The evidence to date. Int. J. Clin. Pract. 2016, 70, 886-897. [CrossRef]

17. Sperber, C.M.; Samarasinghe, S.R.; Lomax, G.P. An upper and lower bound of the Medication Possession Ratio. Patient Prefer. Adherence 2017, 11, 1469-1478. [CrossRef] [PubMed]

18. Ference, B.A.; Ginsberg, H.N.; Graham, I.; Ray, K.K.; Packard, C.J.; Bruckert, E.; Hegele, R.A.; Krauss, R.M.; Raal, F.J.; Schunkert, H.; et al. Low-density lipoproteins cause atherosclerotic cardiovascular disease. 1. Evidence from genetic, epidemiologic, and clinical studies. A consensus statement from the European Atherosclerosis Society Consensus Panel. Eur. Heart J. 2017, 38, 2459-2472. [CrossRef]

19. Baigent, C.; Keech, A.; Kearney, P.M.; Blackwell, L.; Buck, G.; Pollicino, C.; Kirby, A.; Sourjina, T.; Peto, R.; Collins, R.; et al. Efficacy and safety of cholesterol-lowering treatment: Prospective me-ta-analysis of data from 90,056 participants in 14 randomised trials of statins. Lancet 2005, 366, 12671278.

20. Gragnano, F.; Natale, F.; Concilio, C.; Fimiani, F.; Cesaro, A.; Sperlongano, S.; Crisci, M.; Limongelli, G.; Calabrò, R.; Russo, M.; et al. Adherence to proprotein convertase subtilisin/kexin 9 inhibitors in high cardiovascular risk patients. J. Cardiovasc. Med. 2018, 19, 75-77. [CrossRef] [PubMed]

21. Available online: https://www.aifa.gov.it/registri-farmaci-sottoposti-a-monitoraggio (accessed on 15 November 2021).

22. Russo, V.; Cassini, R.; Caso, V.; Donno, C.; Laezza, A.; Naddei, M.; Fiorelli, A.; Golino, P.; Nigro, G. Nursing Teleconsultation for the Outpatient Management of Patients with Cardiovascular Disease during COVID-19 Pandemic. Int. J. Environ. Res. Public Health 2021, 18, 2087. [CrossRef]

23. Russo, V.; Rapacciuolo, A.; Pafundi, P.C.; de Divitiis, M.; Volpicelli, M.; Ruocco, A.; Rago, A.; Uran, C.; Nappi, F.; Attena, E.; et al Cardiac implantable electronic devices replacements in patients followed by remote monitoring during COVID-19 lockdown. Eur. Heart J.-Digit. Health 2021, 2, 171-174. [CrossRef]

24. Monaghesh, E.; Hajizadeh, A. The role of telehealth during COVID-19 outbreak: A systematic review based on current evidence BMC Public Health 2020, 20, 1193. [CrossRef] [PubMed]

25. Zhai, Y.; Wang, Y.; Zhang, M.; Gittell, J.H.; Jiang, S.; Chen, B.; Cui, F.; He, X.; Zhao, J.; Wang, X. From isolation to coordination: How can telemedicine help combat the COVID-19 outbreak? MedRxiv 2020. [CrossRef] 